\title{
CALCAREOUS DEPOSITS ABOUT THE METACARPO-PHALANGEAL JOINTS
}

\author{
A. G. Pollen, London, England \\ From St Mary's Hospital, London
}

The occurrence of calcareous deposits in the supraspinatus tendon and in the abductors of the hip is well recognised, but similar deposits about the metacarpo-phalangeal joints are relatively uncommon and have received scant attention in British publications.

Sandström (1938) reported 329 cases of calcareous deposits in various parts of the body, chiefly in the shoulder and hip regions, but he could find only six cases in which the fingers were involved. He considered that these deposits were of similar origin wherever they occurred, and called the condition myotendinitis calcarea (1951). Carroll, Sinton and Garcia (1955) described 100 cases from the New York Orthopaedic Hospital of deposits in the wrist, hand and fingers, the commonest site being the distal end of the tendon of flexor carpi ulnaris (thirty-seven cases): some of their cases involved the metacarpo-phalangeal joints. Cooper (1942) reported eight cases of deposits about the metacarpo-phalangeal joints, and Key (1949) reported four more. In Great Britain the only cases reported were those of Hitchcock and Langton (1959) who described six cases in the hand and fingers, three of them at the metacarpophalangeal joints. In this paper a further four cases will be described.

\section{CLINICAL PICTURE}

The onset of symptoms is acute, sometimes with mild pyrexia. Pain is often severe, and there may be marked swelling, heat and redness of the affected joint. There is considerable restriction of movement of the finger, due to pain. Thus the condition may simulate infective or gouty arthritis. Sometimes an acutely tender nodule may be felt near to the joint. As a rule the lesion is a solitary one.

Investigations - The erythrocyte sedimentation rate may be increased, though often it is normal. The total and differential white cell count is normal. The serum phosphorus, calcium, uric acid and alkaline phosphatase are within normal limits (Hitchcock and Langton 1959).

Radiographic features-During the acute phase a dense, discrete calcareous mass is seen at one side of the metacarpal head and adjacent to the metacarpo-phalangeal joint (Fig. 1). As the symptoms subside, the deposit becomes less dense and more diffuse (Fig. 2). Eventually the deposit disappears entirely, often within a few months.

Differential diagnosis - The importance of acute infective arthritis in the differential diagnosis of calcareous deposits must be stressed. In Hitchcock and Langton's (1959) series the initial diagnosis was incorrect in the three cases involving the metacarpo-phalangeal joints and antibiotics were given to these patients. Similarly, in the cases to be described in this paper the original diagnosis was acute infective arthritis in three of the four patients, and they were given penicillin for a few days until the significance of the radiographic appearances was appreciated.

The other important feature in the differential diagnosis is the presence of a tender nodule. This was present in two of Hitchcock and Langton's (1959) patients, and was found in one of the cases to be described in this report.

Clinical course-The acute symptoms generally persist for several days and then gradually subside. As the swelling and tenderness diminish, movement returns. A nodule may remain even after all tenderness has gone. 


\section{ETIOLOGY}

There seems little doubt that these calcareous deposits are similar to those occurring in tendinous tissue elsewhere, and that the causative factors are the same. Cooper (1942) examined the lesions microscopically and found degenerative changes in fibrous tissue and some narrowing of arterial lumina. Sometimes "foreign body" giant cells were seen. He suggested that the primary lesion was degenerative, possibly from local ischaemia, and that the deposition of calcium salts occurred secondarily.

Injury does not seem to be an important factor in determining the onset. Carroll, Sinton and Garcia (1955) obtained a history of injury in only a third of their cases. Seidenstein (1950) and Cooper (1942) did not associate the lesion with trauma.

There is no evidence for an infective agent in these cases, though there is an acute aseptic inflammatory process. Antibiotics do not hasten resolution. Calcareous deposits do not appear to be related to gout, and serum uric acid levels are always within normal limits.

\section{TREATMENT}

The lesions are self-limiting and will resolve without specific treatment. Carroll, Sinton and Garcia (1955) found that in untreated patients the acute symptoms subsided in about three weeks. With simple splintage relief was obtained in an average period of nine days. Many of their patients were treated by local injection of 1 per cent procaine into the deposits: the acute symptoms subsided within a few hours. The addition of hyaluronidase, or of hydrocortisone, did not enhance the effect of the local anaesthetic. A number of patients were treated surgically by evacuation of the calcareous deposit. Key (1949) favoured local operation rather than needling, but Cooper (1942) recommended aspiration of the deposit. Other workers (Martin and Brogdon 1957, Sandström 1938, Copland and Michel 1939) have advocated radiotherapy.

Since the condition is self-limiting, simple splinting of the finger should suffice, though injection of procaine may be of value when severe pain persists.

\section{CASE REPORTS}

Case 1-A male clerk aged thirty-three years complained of severe pain and swelling at the base of the left ring finger. He had suffered this for two days, though for a week the finger had been aching a little. There was no history of any injury. Examination revealed considerable swelling over the dorsum of the left hand, related to the fourth metacarpo-phalangeal joint. There was extreme tenderness in this area, and the skin was red and tense. Movements of the finger were severely restricted, and there was some impairment of range in the adjacent fingers.

There was pyrexia of 99.2 degrees Fahrenheit. The white cell count was within normal range, with a normal differential count. The erythrocyte sedimentation rate (Westergren) was 16 millimetres in the first hour. The serum uric acid estimation was 6.5 milligrams per 100 millilitres-within the normal limits. A diagnosis of acute infective arthritis was made and treatment with antibiotics and splintage of the finger was instituted. He was given 600,000 units of procaine penicillin daily for two days.

Radiographs then showed a discrete dense rounded shadow at the radial side of the fourth metacarpal neck (Fig. 1). Penicillin was discontinued and the finger was kept splinted in a position of comfort. Within another three days the pain and swelling were much less severe, and after a further two weeks they had almost completely subsided and movements of the finger were only slightly restricted. Six weeks after the onset of symptoms the only abnormality was a small non-tender nodule in front of the fourth metacarpal head. Radiographs showed the calcification to be much less dense, and more diffuse (Fig. 2). Fifteen months

VOL. 43 B, NO. 2, MAY 1961

C 


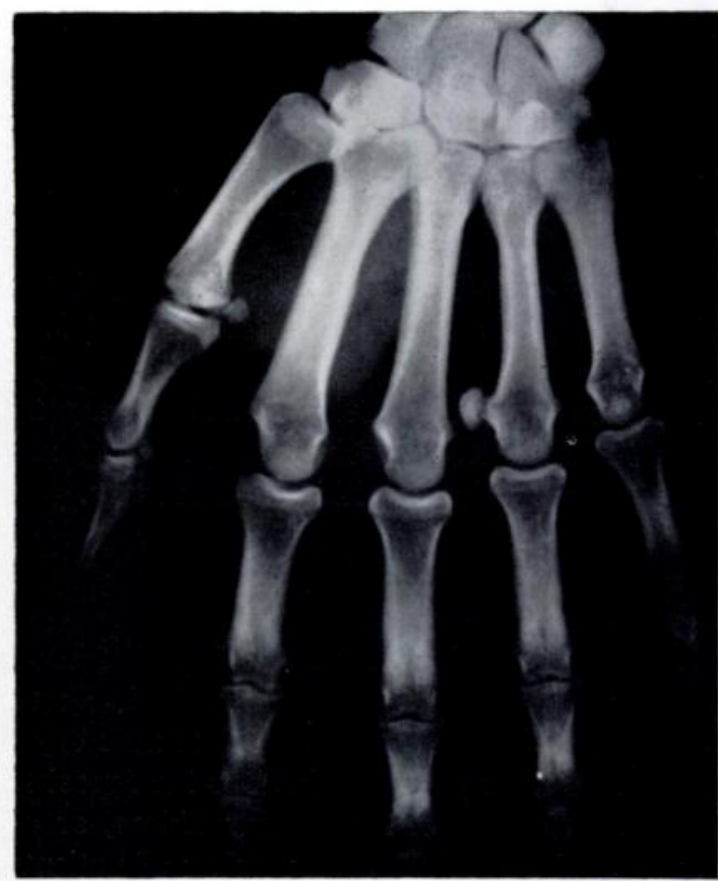

FIG. 1

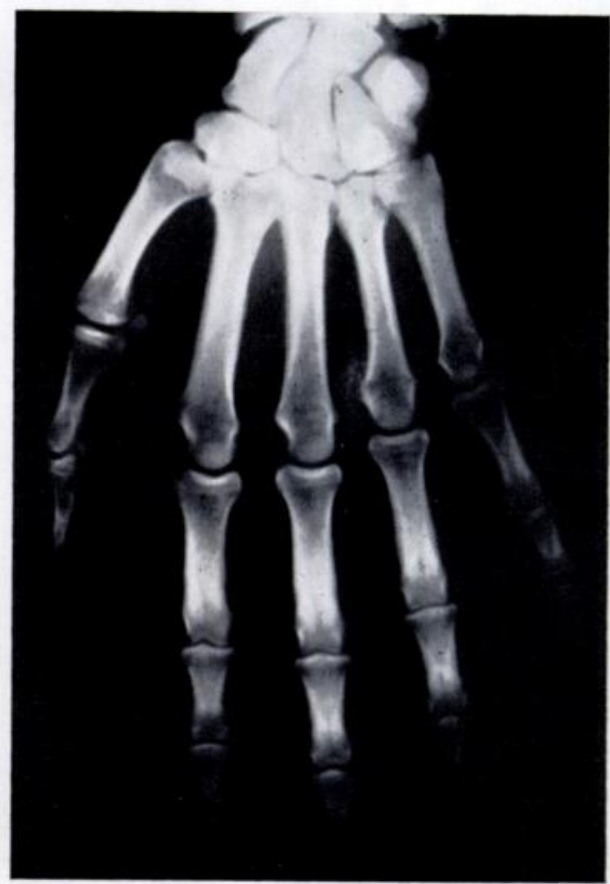

FIG. 2

Case 1. Figure 1-Radiograph of left hand showing dense calcareous deposit to the radial side of the fourth metacarpal head. Figure 2 -The same hand six weeks later, showing faint speckled calcification.

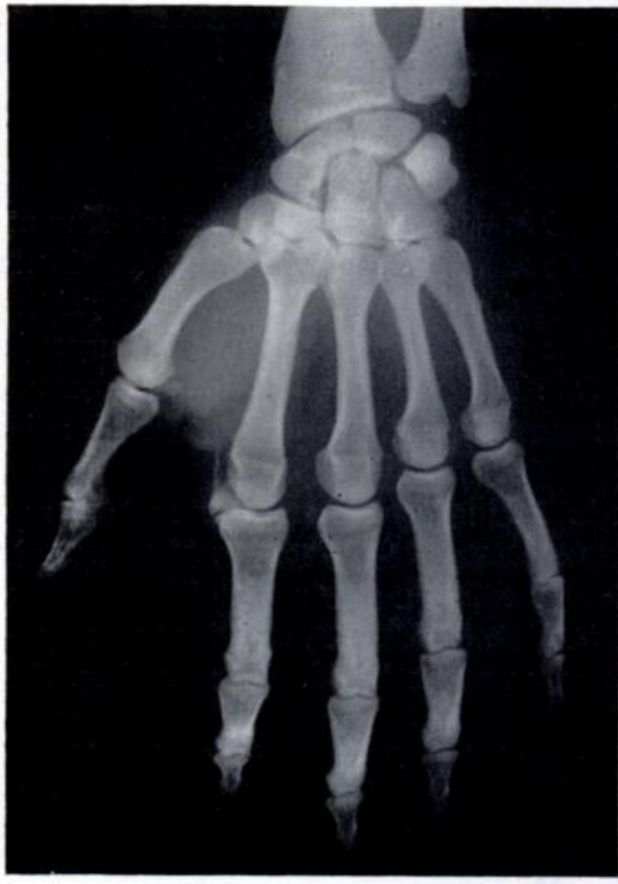

FIG. 3

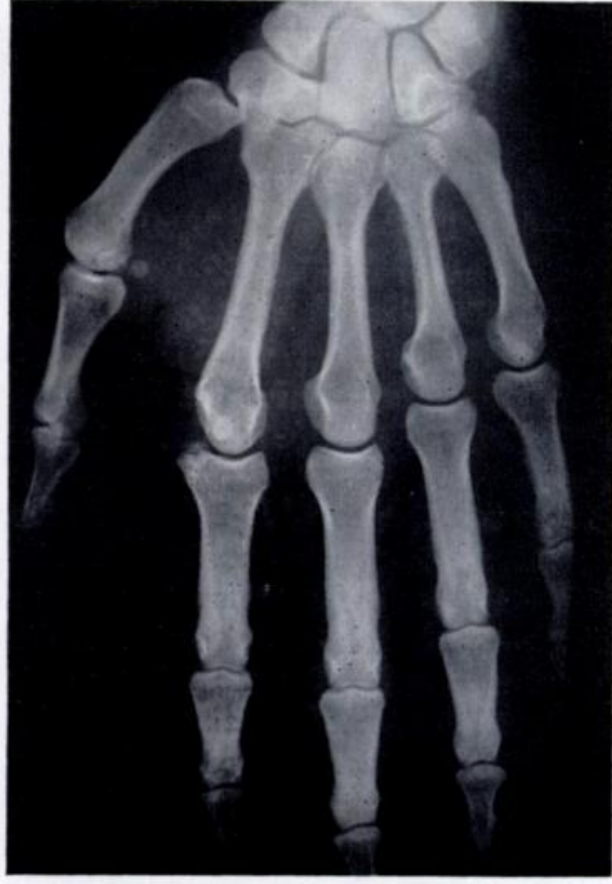

FIG. 4

Case 2. Figure 3-Radiograph of left hand showing calcareous deposit to the radial side of the second metacarpo-phalangeal joint. Figure 4 - Radiograph of the same hand five weeks later. The calcification has almost disappeared. 
later the hand was clinically normal and the nodule had disappeared: radiographs showed no sign of calcification.

Case 2-A sales representative aged forty-two years complained of aching about the base of the left index finger. He gave a rather vague history of minor injury to the hand two months before. On examination there was slight swelling of the metacarpo-phalangeal joint of the index finger, with some restriction of movement. There was no pyrexia. Radiographs of the hand showed a lobulated shadow, with a proximal "tail," lying antero-laterally to the metacarpo-phalangeal joint of the index finger (Fig. 3). Two days later, while in another part of the country, the symptoms became much more severe. He was admitted to the local hospital, where he was thought to have infective arthritis and was given penicillin $(250,000$ units three-hourly) for three days. The finger was splinted. Thereafter he returned to London, with less pain but still with considerable swelling and restriction of joint movement. The finger was rested for a further four days, by which time the pain had almost gone. He then attended for local short-wave diathermy and movements were encouraged.

Five weeks after the onset of acute symptoms the pain had completely gone and finger movements were full. A radiograph showed only faint speckled calcification (Fig. 4). Two years later the finger was clinically normal, and radiographs showed no sign of the original calcareous deposit.

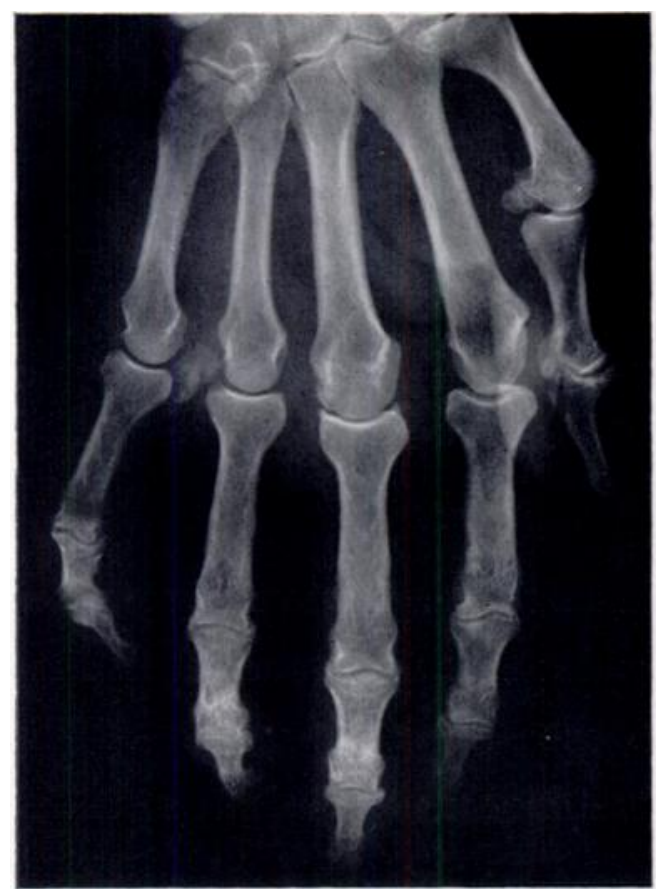

Fig. 5

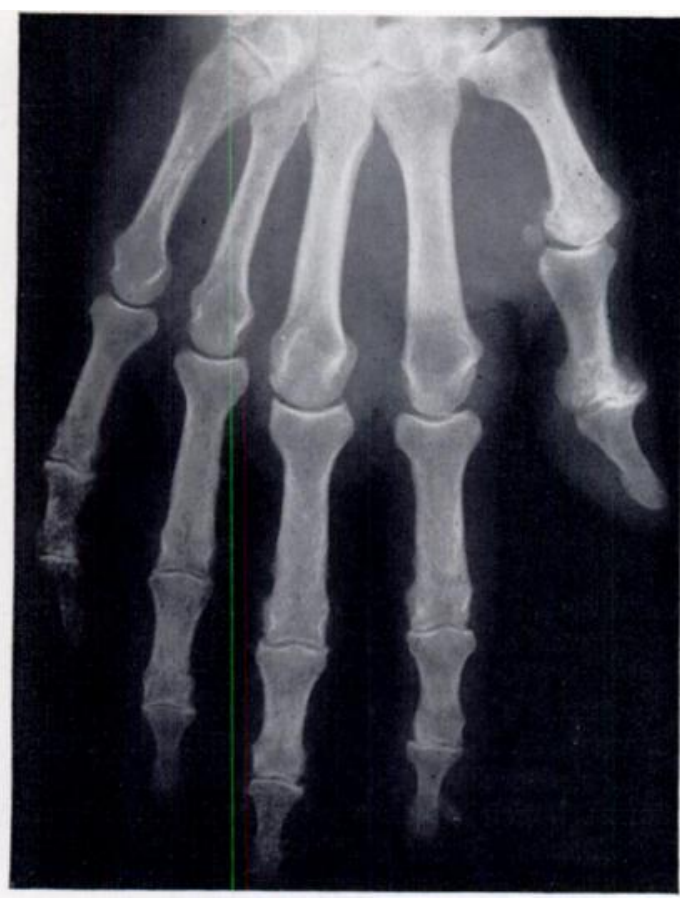

Fig. 6

Case 3. Figure 5-Radiograph of right hand showing a large calcareous deposit near the fifth metacarpophalangeal joint. Figure 6-Radiograph of the same hand four months later showing complete absorption of the deposit.

Case 3-A woman aged seventy-four years fell and injured her right hand. Five days later she reported with severe pain about the base of the right little finger. On examination there was marked swelling over the dorsum of the fifth metacarpo-phalangeal joint, with extreme tenderness between the fourth and fifth metacarpal heads. Movements of the little and ring fingers were restricted and painful. Her temperature was 100.6 degrees Fahrenheit and the clinical picture suggested infective arthritis of the fifth metacarpo-phalangeal joint. Treatment by local splinting and procaine penicillin $(600,000$ units daily) was instituted.

vOL. 43 B, NO. 2, MAY 1961 
Radiographs taken the next day showed a dense irregular calcareous deposit at the radial side of the fifth metacarpo-phalangeal joint. There were degenerative changes at the interphalangeal joints, but no bony injury (Fig. 5). Penicillin injections were continued for two days. After nine days all pain and swelling had gone and movements were fully restored. Four months later the finger was entirely normal and a radiograph showed that the calcareous deposit had been absorbed (Fig. 6).

Case 4-A male medical practitioner aged thirty-one noticed an aching pain around the third metacarpo-phalangeal joint of the left hand. Radiographs showed a bilocular dense calcareous deposit to the radial side of the third metacarpo-phalangeal joint. No treatment was prescribed because the symptoms were slight.

About six months after this mild onset, sudden severe symptoms developed. The joint became exquisitely painful, tender and swollen, and any movement of the finger exacerbated the pain. Further radiographs were taken. The calcareous deposit was still present, but its outline was not so sharply defined and it was less dense. The serum uric acid was within normal limits. The patient was at first treated for gouty arthritis with hourly doses of colchicine by mouth. No dramatic improvement in the symptoms ensued, though a severe toxic reaction followed the cessation of colchicine therapy. The pain and swelling of the joint gradually subsided in about seven days without further treatment, and complete recovery followed. A radiograph taken eleven months later showed complete disappearance of the calcareous deposit.

\section{SUMMARY}

1. Previous reports of calcareous deposits about the metacarpo-phalangeal joints are reviewed, and four further cases are described.

2. The clinical features are described, with reference to the possibility of erroneous diagnosis.

3. Conservative treatment is recommended.

I am grateful to $\mathrm{Mr} \mathrm{J}$. C. Adams for his help and encouragement in the preparation of this paper. I wish to thank Mr Rodney Sneath for giving me the details of the patient in Case 3, whom he treated. I would like to express my thanks to Dr P. N. Cardew and the staff of the Photographic Department of St Mary's Hospital for reproduction of the radiographs.

\section{REFERENCES}

Aitken, A. P., and Magill, H. K. (1951): Calcareous Tendinitis of the Flexor Carpi Ulnaris. New England Journal of Medicine, 244, 434.

Boss,, R. (1954): Peritendinitis Calcarea with Multiple Foci in the Finger Joints of a Young Subject. British Journal of Radiology, N.S. 27, 692.

Carroll, R. E., Sinton, W., and Garcia, A. (1955): Acute Calcium Deposits in the Hand. Journal of the American Medical Association, 157, 422.

Cohen, I. (1924): Calcareous Deposit at the Insertion of Flexor Carpi Ulnaris Tendon Following Trauma. American Journal of Surgery, 38, 172.

COOPER, W. (1942): Calcareous Tendinitis in the Metacarpo-phalangeal Region. Journal of Bone and Joint Surgery, 24, 114.

Copland, S. M., and Michel, M. (1939): Peritendinitis Calcarea. New Orleans Medical Journal, 92, 261.

De Palma, A. F. (1947): Calcareous Deposits in Soft Tissues About the Proximal Interphalangeal Joint of the Index Finger. Journal of Bone and Joint Surgery, 29, 808.

Gondos, B. (1953): Calcification About the Wrist with Acute Pain. (Periarthritis Calcarea). Radiology, 60, 244.

Gondos, B. (1957): Observations on Periarthritis Calcarea. American Journal of Roentgenology, 77, 93.

Hamilton, A. R. (1951): Calcinosis. Journal of Bone and Joint Surgery, 33-B, 572.

Hitchсоск, E. R., and Langton, L. (1959): Peritendinitis Calcarea with Special Reference to the Hand. Journal of the Faculty of Radiologists, 10, 86.

Hгтснсоск, Н. Н. (1937): Calcium Deposits About Joints. Western Journal of Surgery, Obstetrics and Gynecology, 45, 353.

Jansen, K. F. (1943): Calcareous Peritendinitis. Two Cases with Localisation to the Fingers. Acta Radiologica, 24, 285. 
Key, A. J. (1949): Calcium Deposits in the Vicinity of the Shoulder and of Other Joints. Annals of Surgery, 129, 737.

LAPIDUs, P. W. (1943): Infiltration Therapy of Acute Tendinitis with Calcification. Surgery, Gynecology and Obstetrics, 76, 715.

Martin, J. F., and Brogdon, B. G. (1957): Peritendinitis Calcarea of the Hand and Wrist. American Journal of Roentgenology, 78, 74.

MASERITZ, I. H. (1935): Acute Intermetacarpophalangeal Calcification. Journal of Bone and Joint Surgery, $17,1,017$.

Milch, H., and Green, H. H. (1938): Calcification About the Flexor Carpi Ulnaris Tendon. Archives of Surgery, 36, 660.

Oldfield, M. C. (1951): “Tennis Thumb” Tendinitis with Calcification in Flexor Pollicis Longus. Lancet, i, 1,151 .

Phalen, G. S. (1952): Calcification Adjacent to the Pisiform Bone. Journal of Bone and Joint Surgery, 34-A, 579.

Sandström, C. (1938): Peritendinitis Calcarea. A Common Disease of Middle Life: Its Diagnosis, Pathology and Treatment. The American Journal of Roentgenology, 40, 1.

Sandström, C. (1951): Calcification of the Intervertebral Discs and the Relationship Between Various Types of Calcifications in the Soft Tissues of the Body. Acta Radiologica, 36, 217.

Seidenstein, H. (1950): Acute Pain in the Wrist and Hand Associated with Calcific Deposits. Journal of Bone and Joint Surgery, 32-A, 413.

Shephard, E. (1955): Deposit of Calcium Salts at the Wrist. Report of Two Cases. Journal of Bone and Joint Surgery, 37-B, 453.

VASKo, J. R. (1946): Calcareous Tendinitis of a Flexor Tendon of the Finger. Journal of Bone and Joint Surgery, 28, 638.

Winchester, J. W., and Mekie, E. C. (1947): Tendinitis of Flexor Carpi Ulnaris. British Journal of Radiology, N.S. $20,482$. 